\title{
La comida de Jesús en casa de Simón el Fariseo de Rubens y su influencia en dos obras malagueñas
}

\author{
Julio Morales Folguera \\ Universidad de Málaga \\ juliomorales.53@hotmail.com
}

La unción de Cristo fue recogida en los cuatro evangelios. Hay dos unciones distintas: una ocurrida en Betania, y recogida por Mateo y Marcos sobre la cabeza, y por Juan sobre Ios pies; y otra, relatada por Lucas, sobre los pies, que se diferencia de los anteriores evangelistas al no hacer alusión al empleo del perfume para el día de la sepultura.

En ninguna de las escenas evangélicas de la unción se menciona a María Magdalena como la mujer que ungió a Jesús. Sin embargo, fue el papa Gregorio Magno (540-604) quien estableció que la mujer «pecadora» de Lucas, María de Betania y María Magdalena eran la misma persona. Así mismo, hay que citar el éxito de la Leyenda dorada, compendio hagiográfico redactado en latín en 1264 por el dominico italiano Santiago de la Vorágine, que explicaría que en la Baja Edad Media se hiciera a la Magdalena protagonista de la unción, incluyendo este episodio en los ciclos dedicados a la santa de Magdala (González, 2014: 83).

Los artistas en general se decantaron mayoritariamente por representar a la mujer derramando el perfume sobre los pies de Cristo, lavándolos con sus lágrimas y enjugándolos con sus cabellos; y fueron muy pocos los que optaron por representar a María Magdalena derramando perfume sobre la cabeza del Señor (González, 2014: 84-85).

La representación de Jesús en casa de Simón el Fariseo plasma la escena narrada por el evangelista Lucas (7, 36-50). Simón el Fariseo ${ }^{1}$ invitó a Jesús a comer a su casa. $Y$ he aquí que había en la ciudad una mujer «pecadora» que, al enterarse de que Jesús estaba sentado a la mesa en casa del fariseo, llevó un vaso de alabastro con perfume, se puso detrás a sus pies llorando y comenzó a bañarlos con sus lágrimas, los enjugó con sus cabellos, los besó y los ungió con el perfume.

Viendo esto el fariseo que lo había invitado, decía para sí: Si este fuera profeta, sabría con certeza quién y qué clase de mujer es la que le toca: que es una pecadora. A esta aseveración, Jesús le contestó por medio de una parábola:

Un prestamista tenía dos deudores: el uno le debía quinientos denarios, y el otro cincuenta. No teniendo estos con qué pagar, se lo perdonó a los dos. ¿Cuál de ellos le amará más? Simón contestó: Estimo que aquel a quien perdonó más. Entonces Jesús le dijo: Has juzgado con rectitud. Y vuelto hacia la mujer, dijo a Simón: ¿Ves a esta mujer? Entré en tu casa y no me diste agua para los pies; ella en cambio ha bañado mis pies con sus lágrimas y los ha enjugado con sus cabellos. No me diste el beso; pero ella, desde que entré no ha dejado de besar mis pies. No has ungido mi cabeza con óleo; ella en cambio ha ungido mis pies con perfume. Por eso te digo: le son perdonados sus muchos pecados, porque ha amado mucho. Aquel a quien menos se perdona menos ama. Entonces le dijo a ella: Tus pecados quedan perdonados (LC 7, 41-49).

La mujer pecadora², movida sin duda por la gracia, acudió atraída por la predicación de Cristo y lo que se decía de Él. Los invitados se ponían a la mesa apoyados sobre el brazo izquierdo, en pequeños divanes, de forma que los pies quedaban retirados hacia afuera. Eran deberes de cortesía para con el huésped darle el beso de bienvenida, ofrecerle agua para lavarse los pies, y perfumes con que ungirse (Sagrada Biblia, tomo III, 1990: 191). 


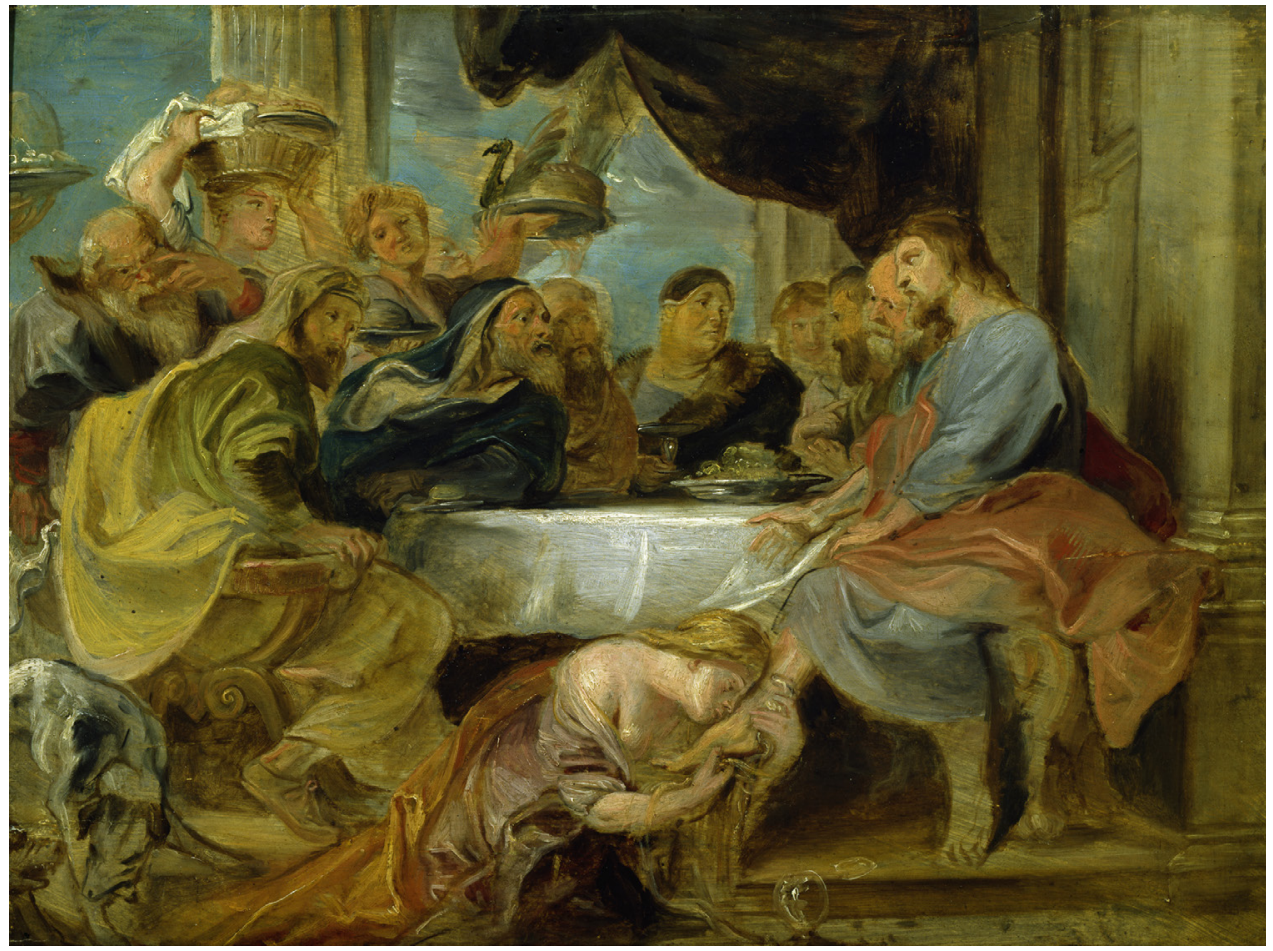

1. Pedro Pablo Rubens (atrib.), Comida de Jesús en casa de Simón el Fariseo. c. 1618. Óleo sobre tabla. Gemälde-Galerie, Akademie der Bildenden Künsten, de Viena
Tres cosas enseña Cristo en la breve parábola de los dos deudores: su divinidad y el poder de perdonar los pecados, el mérito del amor de la pecadora y la desatención que encierran los descuidos de Simón, quien ha omitido en el trato con Jesús los detalles de urbanidad que se solían tener con los invitados. El Señor no buscaba esos detalles por el valor que en sí poseían sino por el cariño que ellos expresaban, y por eso se duele de la falta de atención de Simón (Sagrada Biblia, tomo III, 1990: 192).

\section{Precedentes iconográficos}

A comienzos del siglo XVI empiezan a aparecer las primeras obras que representan el tema de la Comida de Jesús en Betania. No obstante, el creador del modelo iconográfico que va a aparecer en dos grandes lienzos ubicados en las ciudades de Málaga y Ronda es el pintor flamenco Pedro Pablo Rubens. En fecha indeterminada, aunque seguramente en torno a 1618, Rubens realiza un pequeño cuadro al óleo sobre madera con $31 \times 41,5 \mathrm{~cm}$, que carece de su firma ${ }^{3}$. Esta obra se halla en la Gemälde-Galerie, Akademie der Bildenden Künsten, de Viena [1]. Como solía hacer con frecuencia, Rubens crea con esta obra el diseño original de la composición del tema de La comida de Jesús en casa de Simón el Fariseo, que después se va a llevar a cabo ya en gran formato en el cuadro, que hoy se halla en el Museo del Hermitage, y que después se utilizaría como base para los grabados que difundirían el tema por todo el orbe católico y que servirían de modelo a otros artistas ${ }^{4}$. Entre 1618 y 1620 Rubens llevó a cabo en su taller el gran cuadro con 189 x $285 \mathrm{~cm}$, que se halla en el Museo del Hermitage de San Petersburgo. Esta obra pasó a formar parte del museo ruso en el año 1779, cuando fue adquirida por Catalina la Grande de la colección de Robert Walpole en Houghton Hall, Norfolk $^{5}$. Maria Varshavskaya y Xenia Yegorova han interpretado la obra como un conflicto entre el bien y el mal, entre la virtud y el vicio, donde se exponen los pecados de los fariseos: el orgullo, la hipocresía, la miopía mental o incredulidad, la piedad ostentosa y la codicia [2].

Los grabados que difundieron la obra de Rubens están más próximos al cuadro del Hermitage que al de Viena, aunque mayoritariamente le darían la vuelta a la composición. Se conocen al menos cinco artistas que hicieron plan- 
2. Pedro Pablo Rubens, Comida de Jesús en casa de Simón el Fariseo, 1618-1620.

Óleo sobre lienzo. Museo del Hermitage, San Petersburgo

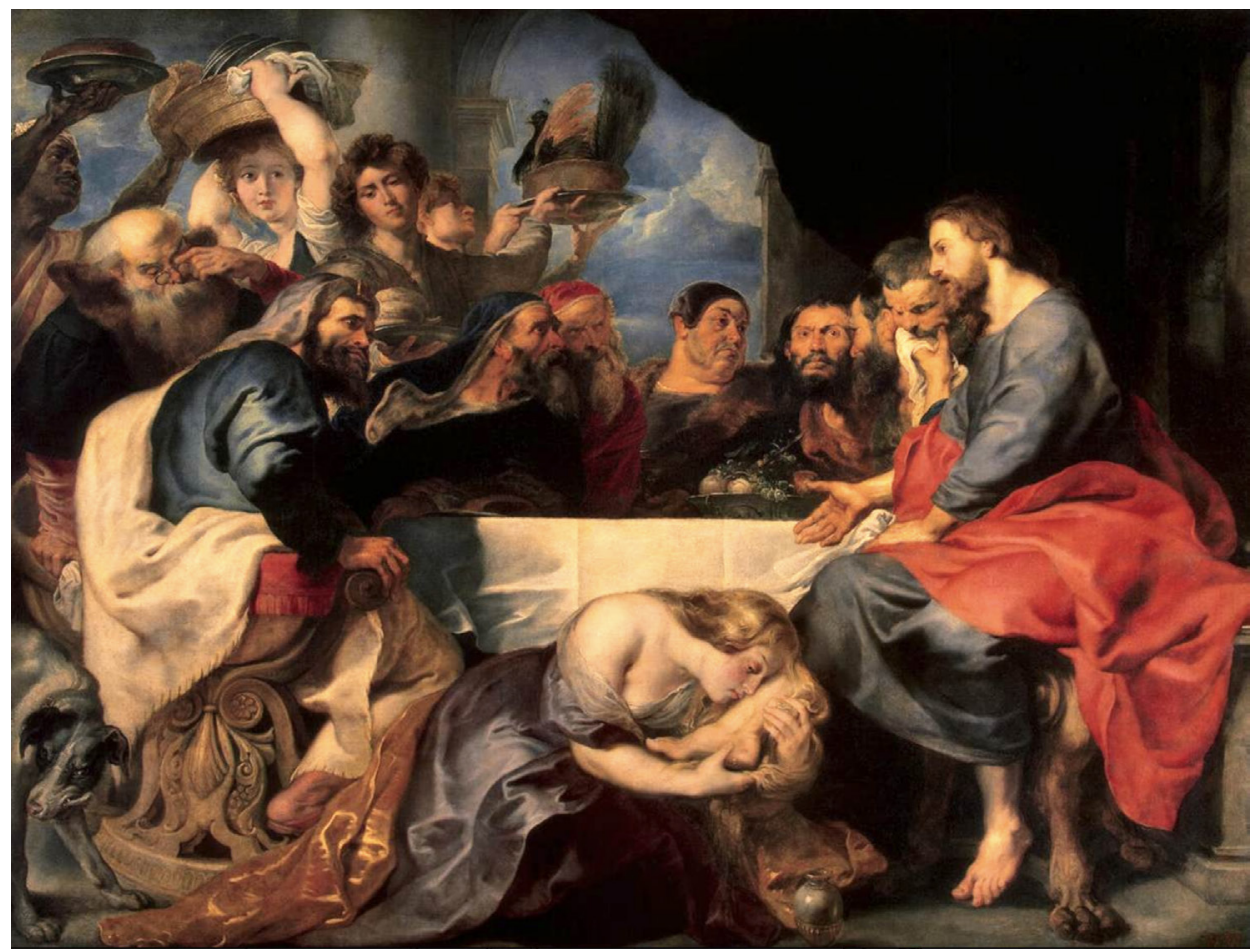

chas grabadas del diseño de Rubens, y varios óleos, que copiaron en mayor o menor medida esos grabados: Michael Natalis (1610-1668), François Ragot (1638-1670), Villen Pannels (h. 1600- h.1634), Richard Earlom (1743-1822), Pietro Monaco (1730-1772), Víctor Wolfvoet el joven (16121652), Artus Wolffort (Amberes, 1581-1641), Peter van Lint (1609-1690).

\section{Anónimo andaluz. Comida de Jesús en casa de Simón el Fariseo. Iglesia del Espíritu Santo. Ronda ${ }^{6}$}

En la sacristía de esta iglesia de la población malagueña de Ronda se conserva un óleo sobre lienzo de grandes dimensiones $(2,70 \times 4,20 \mathrm{~m})$ que representa el tema de la Comida de Jesús en casa de Simón el Fariseo. La obra puede relacionarse con el cuadro de Miguel Manrique, que veremos a continuación, y a través de ella con la obra de Rubens en el Hermitage y con alguno de los grabados que pudieron llegar a Málaga. No obstante presenta ciertas diferencias. El fondo arquitectónico de estilo clasicista está más próximo al modelo de Rubens que al de Manrique, y la composición es la misma con la figura de Cristo y la Magdalena a la derecha. El apóstol junto a la figura de Cristo tiene un paño entre las manos, pero no llega a cubrirse la boca como en la obra de Rubens. También está presente el perro con el hueso a la izquierda y el anciano que se lleva la mano izquierda a las lentes. Del mismo modo en la tarta que llevan los sirvientes se ha eliminado el remate con el pavo real. El ajedrezado del suelo es también novedoso y conecta esta obra con modelos venecianos [3].

Miguel Manrique, La comida de Jesús en casa de Simón el Fariseo, 1642, capilla de San Julián, catedral de Málaga

La llegada a Málaga de Miguel Manrique en 1642 supone un factor importante en la renovación de la estética pictórica de la ciudad, al introducir la influencia de la escuela de Rubens (Pérez, 1998: 73), en la que se había formado durante los años de estancia en Flandes ${ }^{7}$. Ese mismo año firma la obra de La comida de Jesús en casa de Simón el Fariseo, que fue encargada por el conde de Mollina para 


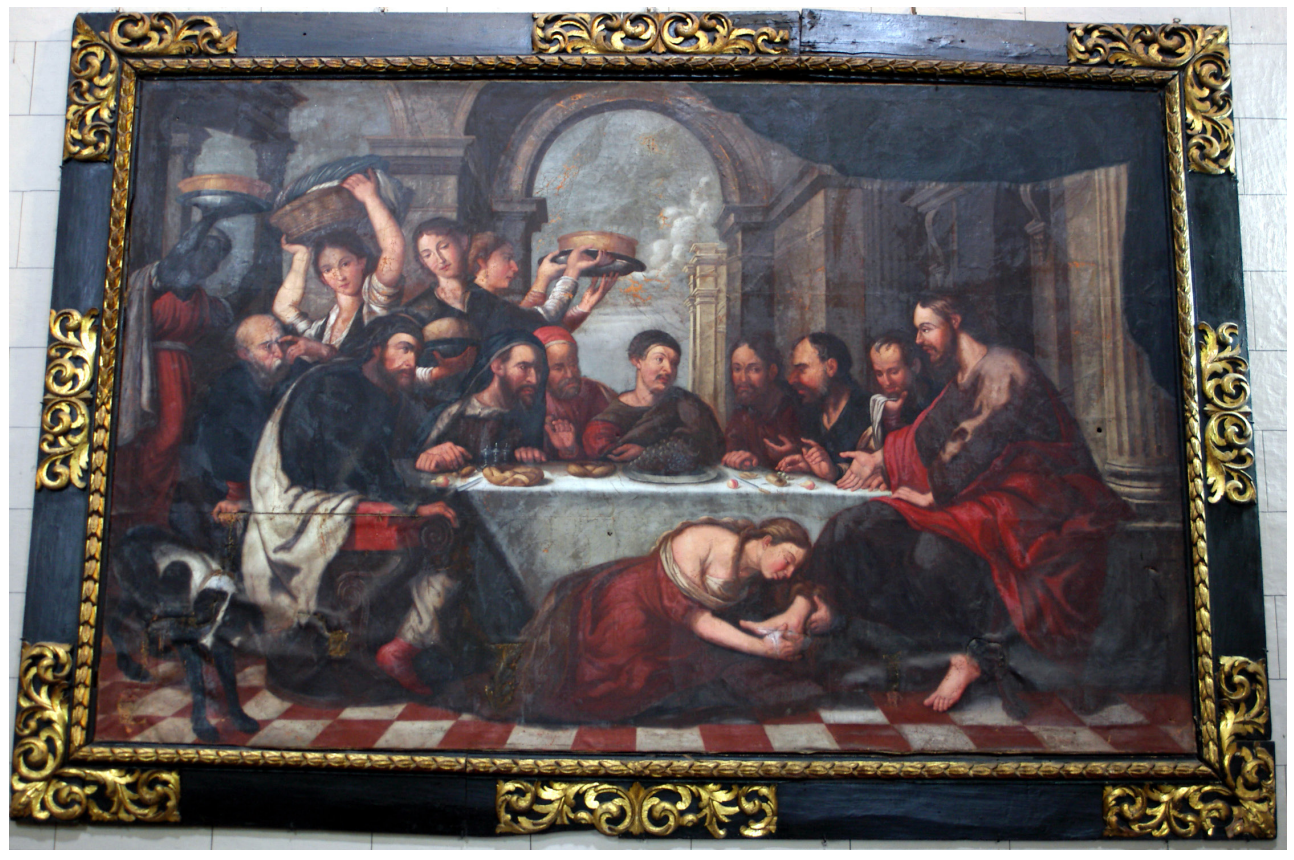

3. Anónimo andaluz. Comida de Jesús en casa de Simón el Fariseo. Segunda mitad siglo XVII. Óleo sobre lienzo. Iglesia del Espíritu Santo. Ronda el refectorio del convento de los Mínimos y que hoy se encuentra en la catedral de Málaga ${ }^{8}$. A pesar de hallarse en la clausura, la presencia de este impresionante cuadro debió suponer un revulsivo importante para la cultura artística malagueña y especialmente para su discípulo Juan Niño de Guevara (Clavijo, 1998), calificado por Pérez Sánchez como el pintor «más significativo de la segunda mitad del siglo». Ceán Bermúdez dice que el obispo de Málaga al observar sus cualidades lo puso «baxo la dirección y enseñanza del capitán D. Miguel Manrique» (Ceán, 1800, t. III: 233). Con esta obra puede relacionarse la presencia del cuadro anónimo con el mismo tema en la iglesia del Espíritu Santo de Ronda.

Pero la llegada de la estética flamenca a Málaga se produce no solo por la presencia de Manrique ${ }^{9}$, cuyas obras en su mayoría fueron destruidas y desaparecieron en los años 1931 y 1936 (González, 2003, 369-379), sino también por el uso de artistas locales de estampas creadas en las imprentas flamencas por grabadores como Schelte a Bolswert (ca. 1586-1659), Paolus Pontius (1603-1658), François Ragot (1638-1670), Michael Natalis (1610-1668), Willem Panneels (h. 1600-h. 1634), y especialmente Hendrick Goltzius (1558-1616), quien inspiró cuatro apostolados de iglesias y conventos malagueños (Escalera y Morales, 2021).
El primero que habla de Miguel Manrique y de su obra es Antonio Ponz en el tomo XVIII de su Viage de España, (1794: 190-191). En 1800 Ceán Bermúdez (1800: 232-233) escribe que el obispo fray Antonio Henríquez puso en contacto a Juan Niño de Guevara con Miguel Manrique. En 1894 el canónigo y académico correspondiente de la Real Academia de la Historia Miguel Bolea y Sintas (1894: 277) establece el año de 1835 como el momento de la llegada del cuadro de Manrique a la catedral de Málaga. Otros autores como Llordén (1959: 145) y Amador de los Ríos (1907: 205) piensan que la obra fue traslada en 1839 o en 1845, respectivamente ${ }^{10}$. Durante el último siglo la obra ha sido restaurada dos veces: la primera en 1945 por la Dirección General de Bellas Artes de Madrid y la segunda en 2011 en las dependencias del Centro de Intervención del Instituto Andaluz de Patrimonio Histórico (Cansino, 2008: 16-43).

A diferencia de otras obras atribuidas a Manrique sobre las que hay dudas, este cuadro (con unas dimensiones de 2,77 x 5,69 m) no plantea dudas, ya que aparece firmado y fechado en el pedestal de la columna salomónica de la derecha: Mlg Mariq pinxt An. ${ }^{\circ} 1642$ (Clavijo, 1994: 542).

A pesar de que la mayoría de los estudios afirman que la obra de Manrique se basa en alguno de los grabados que difundieron la obra de Rubens, la composición se inspira 


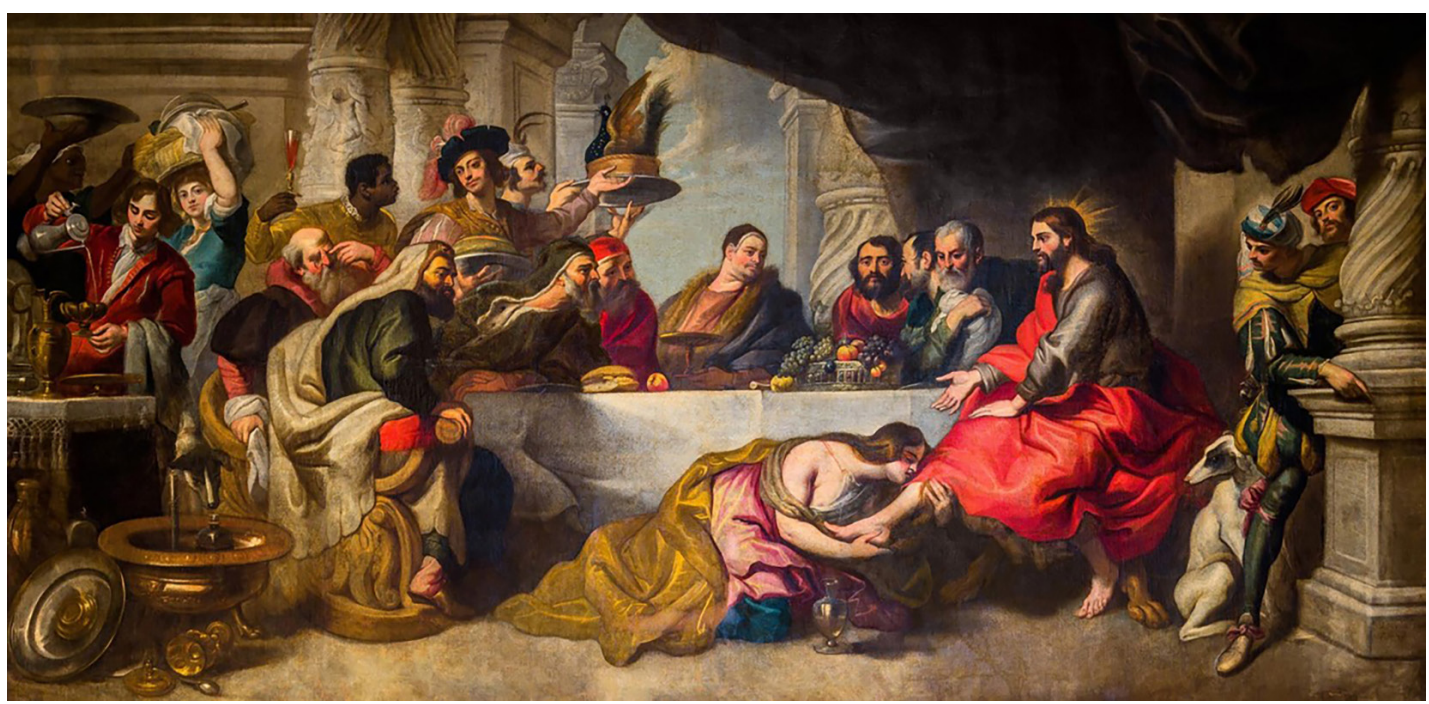

4. Miguel Manrique, La comida de Jesús en casa de Simón el Fariseo, 1642. Óleo sobre lienzo. Capilla de San Julián, catedral de Málaga

tanto en la tablita de la Gemälde-Galerie como en el lienzo del Hermitage. La composición no está girada como en las estampas, pero presenta importantes diferencias con respecto a los modelos, tanto en la parte central del cuadro, como en los dos añadidos laterales. Cristo y la Magdalena se hallan a la derecha. Junto a Jesús hay tres discípulos, pero el que está junto a él no se cubre la boca con el paño. En el centro de la composición está Simón el Fariseo, que sujeta una gran copa de cristal y gira su cabeza hacia Cristo. Algunos autores han especificado que su rostro es un retrato del conde de Mollina, pero en realidad es una fiel copia de Rubens. A su derecha están los tres fariseos, destacando por su ampuloso gesto el que se cubre con un taled blanco. Detrás está el anciano, que se lleva la mano a las lentes. El grupo de los sirvientes ha aumentado hasta seis, con dos de raza negra ${ }^{11}$, dos se cubren la cabeza con gorros, por lo que más que sirvientes parecen invitados y son los que trasladan la tarta de pavo real. Sus poses elegantes están en consonancia con el vicio que simbolizan: la soberbia. En el primer término del lado izquierdo el pintor ha colocado diversos objetos metálicos y un perro, que olisquea un enfriador de vino -se ve claramente una botella en su interior-, elemento que aparece en pinturas y estampas holandesas y flamencas; como ejemplo podemos citar Mujer en el baño y La mujer hidrópica de Gerrit Dou así como el Bodegón del enfriador de Frans Snyders (colección Fundación Banco Santander) ${ }^{12}$. A la derecha del cuadro, detrás de Jesús, hay un joven con un galgo sentado a sus pies, que señala con su dedo el lugar con la firma de Miguel Manrique sobre el pedestal. El perro con el hueso en la boca, símbolo de la codicia, está ausente. Detrás del joven aparece una cabeza cubierta con un gorro rojo, que tradicionalmente se ha considerado como un autorretrato de Miguel Manrique.

Toda la escena se desarrolla en un marco arquitectónico de columnas salomónicas, que recuerdan otras composiciones de Rubens muy diferentes a las que se pueden observar en los grabados que copian la obra del Hermitage. Lamas-Delgado ha señalado la relación de estas columnas con dos obras de Rubens: La reina Tomyris con la cabeza de Ciro (ca.1622-1623) de Boston, y El Juicio de Salomón de Copenhague (ca. 1617) (Lamas-Delgado, 2018, 200).

Como en el modelo de Rubens, el cuadro de Manrique presenta un mensaje claro: el triunfo de las virtudes de María Magdalena, la pecadora, sobre los vicios de los fariseos, que representan la ortodoxia religiosa de los dirigentes religiosos judíos. 


\section{Notas}

1 Los fariseos constituían un grupo religioso-político muy influyente en Israel. Gozaban de gran prestigio entre el pueblo, ante el que se presentaban como conocedores y escrupulosos observantes de la ley. Creían en la resurrección de los muertos y en la vida futura, a diferencia de los saduceos. Muchos de los escribas y doctores eran fariseos. Después de la destrucción de Jerusalén (70d. C.), el único partido y tendencia del judaísmo fue el fariseísmo. En los Evangelios, los fariseos aparecen, junto a los escribas y saduceos, como los adversarios de Jesús, quien ataca duramente su orgullo, su avaricia, su hipocresía y, sobre todo, el peligro y tendencia permanente de creer que la salvación viene de la ley. Pedro, 1990: 90-91.

2 Esta mujer que Lucas llama «pecadora» no debe confundirse ni con María de Betania, hermana de Marta y de Lázaro, ni con María Magdalena.

3 Legado de Anton Franz von Lamberg-Sprinzenstein al Gemälde-Galerie, Akademie der Bildenden Künsten de Viena en 1822.

4 Rubens llegó a realizar unos 500 bocetos a lo largo de su carrera artística, la mayoría de los cuales se conservan en instituciones como el Louvre, el Hermitage, la National Gallery, el Metropolitan de New York, el Museo Boijsman, el Museo del Prado o la Gemälde-Gallerie. En el año 2018 el Museo Nacional del Prado expuso 73 de estos bocetos, que fueron publicados en un catálogo.

5 «Fiesta en casa de Simón el Fariseo». En: <https:/www.hermitagemuseum.org/wps/portal/hermitage/digital-collection/01.+paintings/48168> (fecha de consulta: 12-11-2020).

6 Guía digital del Patrimonio mueble de Andalucía, n. 248, página 6. Código 212798. Uno de los primeros lugares en los que encontramos este tema en Andalucía es en un relieve de la sillería del coro de la catedral de Sevilla. Este tema se incluirá en una de las vidrieras de la catedral de Málaga en el siglo XIX. Igualmente lo hallamos en un cobre de la catedral de Granada, titulado Unción de María Magdalena a Jesús. Tanto Enrique Valdivieso, como Matías Díaz Padrón y Benito Navarrete han atribuido esta obra a Willem van Herp (h. 1614-1677), quien solo ha tomado de la obra de Rubens algunos elementos: la tarta con el pavo real, el perro con el hueso, que ha colocado en el centro de la composición, y la cabeza de uno de los fariseos. Este mismo autor tiene otro cobre en el Museo del Prado con el tema de Las bodas de Caná, que copia diversos personajes y objetos de la obra de Rubens: el perro con el hueso, los dos fariseos a la izquierda de la mesa, los sirvientes con las bandejas, entre ellos el sirviente negro, la tarta con el pavo real, el personaje de la derecha con el gorro, que gira la cabeza a su izquierda, inspirado en Simón el Fariseo, al igual que la arquitectura clasicista del fondo. Agradezco la información facilitada por el profesor Rafael López Guzmán.

7 La recuperación de la figura de Miguel Manrique en la historiografía contemporánea malagueña se debe inicialmente al padre Andrés Llordén, quien ya en 1947 publicó un primer artículo en la revista «La ciudad de Dios», vol. 159, pp. 513-546. Más tarde publicó en la revista Gibralfaro, n. 9, 12 y 13, los documentos encontrados en el Archivo de Protocolos de Málaga. Finalmente, todos estos datos anteriores fueron recogidos en su libro sobre los Pintores y doradores malagueños, 1959, pp. 130-149. Con posterioridad hay que señalar las aportaciones llevadas a cabo por el profesor Agustín Clavijo, que quedaron publicadas en su tesis doctoral sobre la Pintura barroca en Málaga y su provincia, tomo II, pp. 480-559. En 2018 Eduardo Lamas-Delgado ha dedicado un nuevo estudio al hispanoflamenco Miguel Manrique-Michele Fiammmingo, nacido ca. 1610/1612 en la población de Marche-en-Famenne.

8 En la catedral de Málaga se conservan otras obras de estilo flamenco como la Piedad de Cornelis de Vos, la Virgen con el Niño del estilo de Jan Brueghel de Velours, y series de cobres con escenas evangélicas, como la formada por los ocho óleos firmados por Peter Sion, que se inspiran en Rubens, al igual que otras obras existentes en iglesias y conventos de Antequera y Ronda.

9 En la catedral de Málaga se conservan siete grandes lienzos anónimos flamencos del siglo XVII con alegorías de las Virtudes, que fueron donados en 1885. 10 Amador de los Ríos afirma en la página 859 que «el 28 de febrero de 1845, D. Melchor Ordóñez, Gobernador de Málaga, comunica a la Comisión Central de Monumentos...que fueron depositados en la catedral, el lienzo de Manrique El convite del Fariseo [...]”.

11 Andrés Llordén en su artículo de la revista Gibralfaro, n. ${ }^{\circ}$ 13, afirma que el joven negro, situado junto al sirviente con el sombrero, era un esclavo llamado Francisco, el cual le servía como modelo. Esta era una práctica habitual entre los pintores españoles y es una prueba de la importante población de origen africano que vivía en España en el siglo XVII. Era también un signo de riqueza.

12 Agradezco las referencias a Alejandro Vergara, así como a Pilar Benito y a Rafael Sánchez-Lafuente por su implicación.

\section{Bibliografía}

AMADOR DE LOS RÍOS, Rodrigo (1907), Catálogo de los monumentos históricos y artísticos de la provincia de Málaga, ejemplares mecanografiados, copia digital realizada por la Biblioteca de Andalucía, 2 vols.

BENEZIT, Emmanuel (1976), Dictionnaire critique et documentaire des peintres, sculpteurs, dessinateurs et graveurs, Librairie Gründ, tomo VII, París.

BOLEA Y SINTAS, Miguel (1894), Descripción histórica que de la catedral de Málaga hace su canónigo doctoral D. Miguel Bolea y Sintas, Arturo Gilabert, Málaga.

CANSINO CANSINO, Amalia, FERRERAS ROMERO, Gabriel y MARTíN GARCÍA, Lourdes (2008), «Investigación y tratamiento del lienzo El convite de Jesús en casa de Simón el Fariseo», Boletín del Instituto Andaluz del Patrimonio Histórico, n. 65, febrero, pp. 16-43.

CEÁN BERMÚDEZ, Juan Agustín. (1800), Diccionario histórico de los más ilustres profesores de las bellas artes en España, Real Academia de San Fernando, Madrid, t. III.

CLAVIJO GARCÍA, Agustín (1975), Juan Niño de Guevara y su obra en la catedral de Málaga, tomo II, Caja de Ahorros Provincial de Málaga, Málaga. 
CLAVIJO GARCÍA, Agustín (1994), La pintura barroca en Málaga y su provincia, tesis doctoral, microfichas, Universidad de Málaga, Málaga. CLAVIJO GARCÍA, Agustín (1998), Juan Niño de Guevara. Pintor malagueño del siglo XVII. Universidad de Málaga, Málaga.

ESCALERA PÉREZ, Reyes y MORALES FOLGUERA, José Miguel (2021), «Viaje solo de ida: la huella del barroco europeo en Málaga», en Universitas. Las artes ante el tiempo. XXIII Congreso Nacional de Historia del Arte, Universidad de Salamanca y Diputación de Salamanca, Salamanca, pp. 836-847.

GONZÁLEZ HERNANDO, Irene (2015), «La unción de Cristo en el imaginario medieval y la exégesis sobre la identidad entre María Magdalena, María de Betania y la pecadora anónima», Revista Digital de Iconografía Medieval, vol. VII, n. ํ.14, pp. 77-96.

GONZÁLEZ TORRES, Javier (2003), «Injerencias artísticas flamencas en la pintura del barroco en Málaga: Miguel Manrique», en VILLAR, M. ${ }^{a}$ Begoña y PEZZI, Pilar (eds.), Los Extranjeros en la España Moderna. I Coloquio Internacional, vol. 2, Gráficas Digarza, Málaga, pp. 369-379.

GRITSAI, Natalia (2011), Van Dyck. 1599-1641, ebook, Parkstone Press, International, Nueva York.

LAMAS-DELGADO, Eduardo (2018), «Miguel Manrique-Michele Fiammingo (ca. 1610/12-1647): un peintre flamand entre Anvers, Gênes et Malaga", Revue Belge d'Archeologie et d'Histoire de l'Art, LXXXVII, 2018, pp. 187-224.

LLORDÉN, Andrés (1959), Pintores y doradores malagueños. Ensayo histórico-documental (siglos XV-XIX). Datos inéditos del Archivo de Protocolos para la historia del arte en la ciudad de Málaga, Ediciones del Real Monasterio de El Escorial, Ávila.

LLORDÉN, Andrés (1961), «El pintor hispano-flamenco Miguel Manrique», Revista Gibralfaro, n. 13, pp. 31-49.

MONZÓN PERTEJO, Elena (2019), «¿Fedeltà o animalidad? El perro en las escenas de conversión de María Magdalena en la Italia del siglo XVl», Boletín de Arte, n. ${ }^{\circ}$ 40, pp. 195-206.

NAVARRETE PRIETO, Benito (2005), «Pinturas y pintores en la catedral», en GILA MEDINA, Lázaro (coord.), El libro de la catedral de Granada, vol. I, Cabildo Metropolitano de la Catedral de Granada, Granada, pp. 315-374.

PEDRO, Aquilino de (1990), Diccionario de términos religiosos y afines, Ed. Verbo Divino, Estella (Navarra).

PÉREZ DEL CAMPO, Lorenzo y ROMERO, José Luis (1986), La catedral de Málaga, Everest, León.

PÉREZ SÁNCHEZ, Alfonso Emilio (1998), «La pintura en la diócesis malagueña», en SÁNCHEZ-LAFUENTE, Rafael (coord.), El esplendor de la Memoria. El arte de la iglesia de Málaga, Junta de Andalucía, Málaga, pp. 70-78.

PONZ, Antonio (1794), Viage de España, tomo XVIII, Viuda de D. Joaquín Ibarra, Madrid.

RENIER, Jean Simon (1866), «Michel Natalis, graveur liégeois», Bulletin de l'Institut Archéologique Liègois, pp. 359-392.

RENIER, Jean Simon (1871), Catalogue de l'oeuvre de Michel Natalis, Vaillant-Carmanne, Liège.

Rubens. Pintor de bocetos (2018), Catálogo de la Exposición celebrada en el Museo Nacional del Prado entre el 10 de abril y el 5 de agosto de 2018, Museo Nacional del Prado, Madrid.

Sagrada Biblia (1990). Tomos I-IV, EUNSA, Pamplona.

TORRES BALBÁS, Leopoldo (1960), La Alcazaba y la Catedral de Málaga, Editorial Plus Ultra, Madrid.

VARSHAVSKAYA, Maria y YEGOROVA, Xenia, Pedro Pablo Rubens. El orgullo de la vida, ebook, Parkstone International, Nueva York. VORÁGINE, Santiago de la (2005), La leyenda dorada, traducción de José Manuel Macías, 2 vols., Alianza Editorial, Madrid. 